
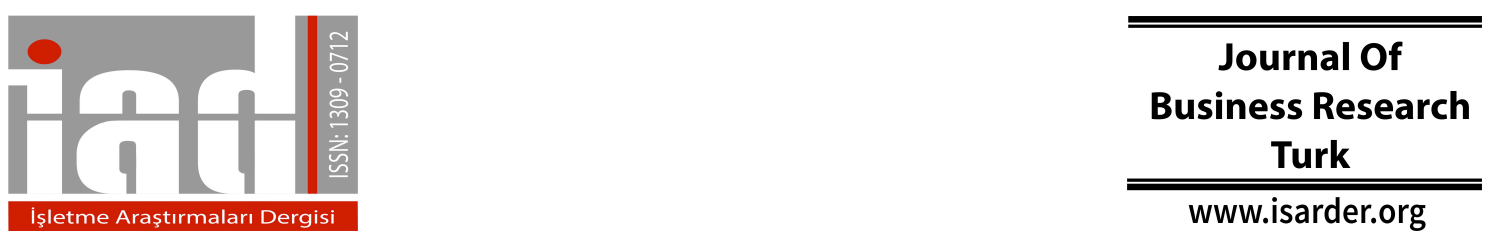

\title{
Examining Consumer Cosmopolitanism and Foreign Travelling in the Context of Consumer Behavior
}

\author{
Aybegüm Güngördü ${ }^{1}$ \\ Bartın University \\ Faculty of Economics and Administrative \\ Sciences, Department of Business \\ Administration \\ Bartın, Turkey \\ aybegum.gungordu@gmail.com
}

\author{
Tuba Yumuşak \\ Gazi University \\ Faculty of Economics and Administrative \\ Sciences, Department of Business \\ Administration \\ Ankara, Turkey \\ t_tokucoglu@hotmail.com
}

\begin{abstract}
Consumer cosmopolitanism drew attention in recent years in the context of shaping consumer behavior. Cosmopolitan consumers tend to travel to foreign countries, frequently. The current study aims to examine consumer cosmopolitanism as an important predictor of consumer behavior such as foreign travelling in Turkey as well as with demographic variables. Our second purpose is to examine foreign travelling as an antecedent of consumer cosmopolitanism as well as with demographic variables. We found that there is a positive and significant relationship between foreign travelling, consumer cosmopolitanism, gender and education. There is a positive and significant relationship between consumer cosmopolitanism, foreign travelling and education. Furthermore, there is a negative and significant relationship between consumer cosmopolitanism and age.
\end{abstract}

Keywords: Consumer cosmopolitanism, foreign travelling, demographic characteristics, cosmopolitan consumers.

\section{Introduction}

The boundaries between home and away, local and global, traditional and nontraditional, have become increasingly blurred in this post-modern world (Skrbis et al., 2004). While this blurry environment continues, "micro culture" consumer segments are created as a reason of migration and cultural heterogeneity in countries (Vida et al., 2008). Cosmopolitanism is an inclination to learn about groups other than their own (Saran and Kalliny, 2012). Cosmopolitanism refers to the ability, attitude, and thinking of a person to learn from other cultures, societies, and nations and the marginal boundaries that distinguish cultures, nations and societies (Saran and Kalliny, 2012). Consumer cosmopolitanism is defined as "world citizenship" and indicates an open

\footnotetext{
${ }^{1}$ First author, Corresponding author.
} 
communication with foreigners and requires being equal to everyone without discriminating people according to their race, religion, culture and citizenship (Altintas et al., 2013). As an opposite of consumer ethnocentrism, consumer cosmopolitanism (Cleveland et al., 2014) attracts attention as a segmentation variable in international markets (Cleveland et al., 2011; Riefler et al., 2012). Studies about consumer cosmopolitanism are such as Cleveland et al., 2009; Cleveland et al., 2011; Parts and Vida, 2011; Saran and Kalliny, 2012; Altintas et al., 2013; Cleveland et al., 2014 and Abraha et al., 2015. As a reason of all these, the present study aims to examine consumer cosmopolitanism as an important predictor of consumer behaviour such as foreign travelling in Turkey as well as with demographic variables. Our second purpose is to examine foreign travelling as an antecedent of consumer cosmopolitanism as well as with demographic variables.

\section{Literature Review}

While being introduced by Merton (1957) as the meaning of "world citizen", cosmopolitanism as a construct looks promosing as compared with consumer ethnocentrism, consumer animosity, consumer patriotism when examining attitudes towards foreign countries (Riefler and Diamantopoulos, 2009). Cosmopolitanism reflects cultural diversity and the predominating tendency towards cultural diversity and cosmopolitans see foreigners as cultural gains (Altintas et al., 2013; Cleveland et al., 2014). Cannon and Yaprak (1993; cited by Altintas et al., 2013) state that cosmopolitan consumers are open to innovations and they evaluate products by looking at their functionality while being free from local effects and traditions. Beck (2002) indicates that cosmopolitan values are over national values for cosmopolitans. Riefler and Diamantopoulos (2009) define cosmopolitan consumers as people who appreciate trying goods and services from different countries and have a consumption tendency which exceeds a specific culture, localness or society. Cosmopolitan consumers have a tendency to buy foreign products compared to local products (Riefler and Diamantopoulos, 2009; Abraha et al., 2015). Some of the cosmopolitanism scales are such as Dye, 1963; Jennings, 1966; Jain and Etgar, 1977; Earle and Cvetchkovich, 1997; Robinson and Zill, 1997; Cannon et al., 1994; Riefler and Diamantopoulos, 2009; Cleveland et al., 2014.

The relationship between consumer cosmopolitanism and foreign travelling is also worth to examine. Yoon (1998) indicates that attributes such as extensive travelling, open mindedness, language abilities, positive thinking, possesion of trendy tastes and wealthy lifestyles are associated with cosmopolitans. Foreign travelling can be an antecedent for consumer cosmopolitanism (Skrbis and Woodward, 2007). A cosmopolitan might have a need to travel and experience different lifestyles (Cannon and Yaprak, 2002). Furthermore, consumer cosmopolitanism can be an antecedent for foreign travelling such as noted by Saran and Kalliny (2012), as the desire to consume cosmopolitanism could fuel a desire to search and consume for travelling. Some authors (Cleveland et al., 2009; Cleveland et al., 2011; Carpenter et al., 2013, Saran and Kalliny, 2012) state that demographic variables such as age, education, gender and income can be predictors of cosmopolitanism. Consumers who have high cultural capital seek to cultivate cosmopolitan tastes (Saran and Kalliny, 2012). Cosmopolitan consumers tend to be open-minded (Yoon, 1998; Skrbis et al., 2004; Riefler and Diamantopoulos, 2009), appreciate diversity (Riefler and Diamantopoulos, 2009, 
Riefler et al., 2012) and consume transcending borders (Riefler and Diamantopoulos, 2009, Riefler et al., 2012).

\section{The Methodology}

At first we carried out a pilot study with 100 consumers to test Cronbach Alpha reliability of the scales. We found that the Cronbach Alpha reliability for the consumer cosmopolitanism scale is 0.918 . Cronbach Alpha reliability for the foreign travelling scale is 0.679 . We had to exclude one item which is reverse coded from the scale to raise the reliability value. Scales were measured on a 5-point Likert Scale $(1=$ definitely not agree; $5=$ definitely agree). Sample characteristics can be seen in Table 1 . Our sample consists of 390 consumers. We used COS/TRAV scale (Cleveland et al., 2014) for our study.

Table 1. Sample Characteristics

\begin{tabular}{|l|l|l|l|l|l|}
\hline & Frequency & $\%$ & Marital Status & Frequency & $\%$ \\
\hline Man & 150 & 38.5 & Single & 308 & 79 \\
\hline Woman & 240 & 61.5 & Married & 82 & 21 \\
\hline Missing & 0 & 0 & Missing & 0 & 0 \\
\hline Income & Frequency & $\%$ & Level of education & Frequency & $\%$ \\
\hline 0-500 Turkish Liras & 140 & 35.9 & Primary education & 4 & 1.0 \\
\hline 501-1500 Turkish Liras & 75 & 19.2 & High school & 10 & 2.6 \\
\hline 1501-2500 Turkish Liras & 16 & 4.1 & Undergraduate & 218 & 55.9 \\
\hline 2501-3500 Turkish Liras & 20 & 5.1 & Post-graduate & 156 & 40 \\
\hline 3501-4500 Turkish Liras & 111 & 28.5 & Missing & 2 & 0.5 \\
\hline 4501 Turkish Liras and over & 8 & 2.1 & & & \\
\hline Missing & 20 & 5.1 & & & \\
\hline Occupation & Frequency & $\%$ & Age & Frequency & $\%$ \\
\hline College student & 231 & 59.2 & $18-25$ & 231 & 59.2 \\
\hline Academic & 47 & 12.1 & $26-30$ & 89 & 22.8 \\
\hline Civil servant & 8 & 2.1 & $31-35$ & 52 & 13.3 \\
\hline Engineer & 11 & 2.8 & $36-40$ & 16 & 4.1 \\
\hline Teacher & 50 & 12.8 & 41 years and older & 2 & 0.5 \\
\hline Other & 27 & 6.92 & Missing & 0 & 0 \\
\hline Missing & 16 & 4.1 & & & \\
\hline
\end{tabular}

\section{Findings}

After the pilot study, we carried out EFA with our sample. Our extraction method is Principal Component Analysis and our rotation method is Varimax with Kaiser Normalization for the exploratory factor analysis. Eigenvalues above 1.0 were considered in the analyses. Only factor loadings of 0.50 or above are reported for EFA as suggested by Hair et al. (1998). Results of the exploratory factor analyses for all of the scales are showed in Table 2. Factor loadings vary between 0.82 and 0.90 for the consumer cosmopolitanism scale. As for the foreign travelling scale, factor loadings vary between 0.67 and 0.83 . 
Table 2. EFA Results

\begin{tabular}{|c|c|c|c|}
\hline Consumer cosmopolitanism & Factor loadings & Foreign travelling & Factor loadings \\
\hline cosmo3 & .904 & foreigntrav5 & .836 \\
\hline cosmo2 & .869 & foreigntrav1 & .790 \\
\hline cosmo4 & .867 & foreigntrav3 & 754 \\
\hline cosmol & .839 & foreigntrav4 & 678 \\
\hline cosmo5 & .825 & & \\
\hline $\begin{array}{l}\text { Total variance explained }=7 \\
0.859, \text { Bartlett's test of Sphe } \\
=1345.017, \mathrm{df}=10, \mathrm{p}<0.05\end{array}$ & $\begin{array}{l}154 \%, \mathrm{KMO}= \\
\text { city Chi Square }\end{array}$ & $\begin{array}{l}\text { Total variance } \\
\text { KMO = } 0.739 \\
\text { Sphericity } \mathrm{Chi} \mathrm{Sq} \\
\mathrm{p}<0.05\end{array}$ & $\begin{array}{lc}\text { ained }= & 58.770 \\
\text { artlett's test } \\
=400.399, \mathrm{df}\end{array}$ \\
\hline
\end{tabular}

After exploratory factor analyses, we carried out confirmatory factor analyses for both scales. Confirmatory factor analyses showed that all of the fit indices are acceptable for both scales which can be seen in table 3. Suggested standards for some fit indices are CMIN/DF $<5$ (Marsh and Hocevar, 1985), RMSEA $<0.08$ (Byrne, 2010), GFI, CFI and IFI $>0.90$ (Bollen, 1989; Bentler, 1992; Engel et al., 2003). Factor loadings were found to be higher than 0.50. Standardized regression weights vary between 0.59 and 0.76 for the foreign travelling scale. For consumer cosmopolitanism scale, standardized regression weights vary between 0.74 and 0.92 . All of the parameters are statistically significant $(\mathrm{t}>1.96)$.

Table 3. CFA Results

\begin{tabular}{|l|l|l|l|l|l|l|}
\hline \multicolumn{7}{|l|}{ Foreign travelling } \\
\hline Path & \multicolumn{2}{l}{ Standardized regression weights } & S.E. & C.R. & P \\
\hline Q5_6 & $<---$ & F1 & .671 & .065 & 11.783 & $* * *$ \\
\hline Q5_8 & $<---$ & F1 & .715 & .076 & 10.867 & $* * *$ \\
\hline Q5_9 & $<---$ & F1 & .599 & .084 & 9.301 & $* * *$ \\
\hline Q5_10 & $<---$ & F1 & .767 & & & \\
\hline CMIN/DF: 1.94 GFI: 0.99 NFI: 0.99 CFI: 0.99 RMSEA: 0.049 & & & \\
\hline Consumer cosmopolitanism & S.E. & C.R. & P \\
\hline Path & \multicolumn{7}{|l|l|l|l|l|l|}{ Standardized regression weights } & .043 & 17.776 & $* * *$ \\
\hline Q5_1 & $<---$ & F1 & .748 & .042 & 19.908 & $* * *$ \\
\hline Q5_2 & $<---$ & F1 & .799 & & & \\
\hline Q5_3 & $<---$ & F1 & .925 & .040 & 20.682 & $* * *$ \\
\hline Q5_4 & $<---$ & F1 & .821 & .050 & 17.422 & $* * *$ \\
\hline Q5_5 & $<---$ & F1 & .743 & & \\
\hline CMIN/DF: 3.57 GFI: 0.98 NFI: 0.99 CFI: 0.99 RMSEA: 0.081 & \\
\hline
\end{tabular}

According to Pearson Correlation results in Table 4, all of the correlations are below 0.80 . Consumer cosmopolitanism is positively and significantly correlated with foreign travelling $(\mathrm{r}=.421, \mathrm{p}<0.01)$, education $(\mathrm{r}=.202, \mathrm{p}<0.01)$ and income $(\mathrm{r}=.177$, 
$\mathrm{p}<0.01)$. Foreign travelling is positively and significantly correlated with consumer cosmopolitanism $(\mathrm{r}=.421, \mathrm{p}<0.01)$, gender $(\mathrm{r}=.228, \mathrm{p}<0.01)$, marital status $(\mathrm{r}=.264$, $\mathrm{p}<0.01)$, age $(\mathrm{r}=.360, \mathrm{p}<0.01)$, occupation $(\mathrm{r}=.302, \mathrm{p}<0.01)$, education $(\mathrm{r}=.390, \mathrm{p}<0.01)$ and income $(\mathrm{r}=.480, \mathrm{p}<0.01)$. As can be seen in table 4, Cronbach Alpha coefficients are above 0.60 suggested by Hair et al. (1998). To test construct validity, we calculated composite reliability for all dimensions and these are reliable as they are above 0.70 suggested by Nunnally and Bernstein (1994). As for convergent validity, AVE values are above 0.50 (Hair et al., 1998; Bagozzi and Yi, 1988). For discriminant validity, square root of each variable's AVE value is greater than the correlation of each dimension with other dimensions (Fornel and Larcker, 1981).

Table 4. Pearson Correlation Results, Mean, SD, AVE, CR and Cronbach Alpha

\begin{tabular}{|c|c|c|c|c|c|c|c|c|c|c|c|c|c|}
\hline & 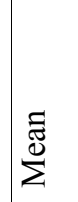 & 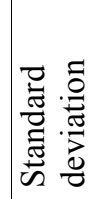 & $\frac{1}{2}$ & $\stackrel{\sim}{0}$ & 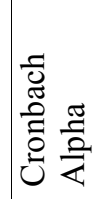 & 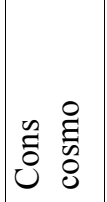 & 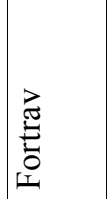 & 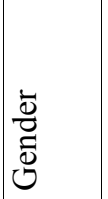 & 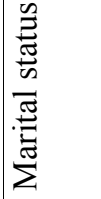 & 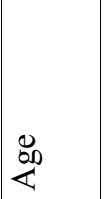 & 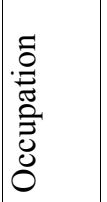 & 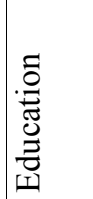 & 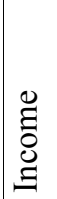 \\
\hline $\begin{array}{l}\text { Cons } \\
\text { cosmo }\end{array}$ & 4.12 & 0.86 & 0.65 & 0.92 & 0.911 & 1 & & & & & & & \\
\hline Fortrav & 3.10 & 1.06 & 0.51 & 0.83 & 0.761 & $.421 * *$ & & & & & & & \\
\hline Gender & 1.38 & 0.48 & - & - & - & .032 & $.228 * *$ & 1 & & & & & \\
\hline Marital status & 1.21 & 0.40 & - & - & - & -.006 & $264 * *$ & $.174 * *$ & 1 & & & & \\
\hline Age & 1.63 & 0.89 & - & - & - & .039 & $.360 * *$ & $.301 * *$ & $.601 * *$ & 1 & & & \\
\hline Occupation & 2.91 & 3.39 & - & - & - & .100 & $.302 * *$. & $.178 * *$ & $.430 * *$ & $.520 * *$ & 1 & & \\
\hline Education & 3.35 & 0.58 & - & - & - & $.202 * *$ & $390 * *$. & $.199 * *$. & $.430 * *$ & $.625 * *$. & $.453 * *$ & & \\
\hline com & 2.75 & 1.76 & - & - & - & $.177 * *$ & $480 * *$ & $02^{\prime}$ & $472 * *$ & $.714 * * 1$. & $.612 * *$ & .702 & \\
\hline
\end{tabular}

Cons cosmo: Consumer cosmopolitanism, fortrav: foreign travelling, AVE: Average variance extracted, CR: Composite reliability (rho).

**. Correlation is significant at the 0.01 level (2-tailed).

We used the multiple regression model to assume the relationship between independent variables which are consumer cosmopolitanism, gender, age, occupation, income, education, marital status and the dependent variable which is foreign travelling. The multiple linear regression approach was adopted for data analysis due to its flexibility in facilitating both discrete and continuously measured predictors (Carpenter et al., 2013). Foreign travelling has a positive and significant relationship between consumer cosmopolitanism, gender and education. According to the multiple regression results, foreign travelling do not have a significant relationship between age, occupation, income and marital status which is shown in table 5. All of the independent variables together explain 37 percent of change in foreign travelling. 
Table 5. Multiple Regression Results I

\begin{tabular}{|c|c|c|c|c|c|c|c|}
\hline \multirow{2}{*}{ Model } & \multicolumn{2}{|c|}{$\begin{array}{l}\text { Unstandardized } \\
\text { Coefficients }\end{array}$} & \multirow{2}{*}{\begin{tabular}{|l|}
$\begin{array}{l}\text { Standardized } \\
\text { Coefficients }\end{array}$ \\
Beta
\end{tabular}} & & \multirow{2}{*}{ Sig. } & \multicolumn{2}{|c|}{ Correlations } \\
\hline & B & Std. Error & & & & $\begin{array}{l}\text { Zero- } \\
\text { order }\end{array}$ & Partial \\
\hline (Constant) & -0.006 & 0.383 & & 0.017 & 0.985 & & \\
\hline \begin{tabular}{|l|} 
Consumer \\
Cosmopolitanism
\end{tabular} & 0.447 & 0.053 & 0.365 & 8.33 & 0.000 & 00.433 & 0.408 \\
\hline Gender & 0.239 & 0.0975 & 0.110 & 2.455 & 0.015 & 50.254 & 0.130 \\
\hline 1 Marital status & 0.132 & 0.139 & 0.050 & 0.949 & 0.343 & 30.263 & 0.050 \\
\hline Age & 0.050 & 0.080 & 0.0432 & 0.619 & 0.536 & 60.369 & 0.033 \\
\hline Occupation & -0.007 & 0.0172 & -0.0247 & 0.455 & 0.649 & 90.299 & $|-0.024|$ \\
\hline Income & 0.051 & 0.112 & 0.0282 & 0.458 & 0.647 & 70.3873 & 0.024 \\
\hline Education & 0.194 & 0.044 & 0.323 & 4.319 & 0.000 & 00.482 & 0.225 \\
\hline
\end{tabular}

Furthermore, we carried out another multiple regression model as can be seen in Table 6 to examine the relationship between the dependent variable consumer cosmopolitanism and independent variables which are foreign travelling, gender, marital status, age, occupation, education and income. According to this model, all of the independent variables together explain 0.22 percent of change in consumer cosmopolitanism. There is a positive and significant relationship between consumer cosmopolitanism, foreign travelling and education. In contrast with Yoon et al. (1996) and similar with Cleveland et al. (2009), Cleveland et al. (2011), Carpenter et al. (2013)'s findings, the finding of the positive and significant relationship between consumer cosmopolitanism and education which means that cosmopolitan consumers are more educated than non-cosmopolitans. We also found that there is a negative and significant relationship between consumer cosmopolitanism and age. This finding is contrast with the studies of Cannon et al. (1994) and Yoon et al. (1996) who found a non-significant relationship between these variables and similar with Cleveland et al. (2009), Cleveland et al. (2011), Carpenter et al. (2013)'s studies. There is not a significant relationship between consumer cosmopolitanism and gender, marital status, occupation and income. The non-significant relationship between consumer cosmopolitanism and income is similar with Cleveland et al. (2009) and Cleveland et al. (2011)'s studies. 
Table 6. Multiple Regression Results II

\begin{tabular}{|c|c|c|c|c|c|c|}
\hline \multirow[t]{2}{*}{ Model } & \multicolumn{2}{|c|}{$\begin{array}{l}\text { Unstandardized } \\
\text { Coefficients }\end{array}$} & \multirow{2}{*}{\begin{tabular}{|l}
$\begin{array}{l}\text { Standardized } \\
\text { Coefficients }\end{array}$ \\
Beta
\end{tabular}} & \multirow[b]{2}{*}{$\mathrm{t}$} & \multicolumn{2}{|c|}{ Correlations } \\
\hline & B & Std. Error & & & Sig. $\begin{array}{l}\text { Zero- } \\
\text { order }\end{array}$ & Partial \\
\hline 1 (Constant) & 2,694 &, 319 & & 8,447 &, 000 & \\
\hline $\begin{array}{l}\text { Foreign } \\
\text { travelling }\end{array}$ &, 372 &, 045 &, 455 & 8,330 & $, 000,433$ &, 408 \\
\hline Gender &,- 070 &, 090 &,- 040 &,- 782 & $, 434,046$ &,- 042 \\
\hline Marital status &,- 183 &, 127 &,- 085 & - & $, 153,012$ &,- 077 \\
\hline Age &,- 151 &, 073 &,- 159 & - 2,053 & $, 041,061$ &,- 110 \\
\hline Occupation &, 018 &, 016 &, 070 & 1,157 & $, 248,139$ &, 062 \\
\hline Education &, 247 &, 102 &, 165 & 2,426 & $, 016,206$ &, 129 \\
\hline Income &,- 016 &, 042 &,- 033 &,- 389 & $, 698,175$ &,- 021 \\
\hline
\end{tabular}

As a result of our research, we can see the effect of a unit change in the independent variable on dependent variable. In the first regression model, consumer cosmopolitanism and gender are the most influential independent variables on dependent variable which is foreign travelling.

Model 1. $\quad \mathrm{y}=-0,006+0,447 \mathrm{x}_{1}+0,239 \mathrm{x}_{2}+0,194 \mathrm{x}_{3}+\mathrm{e}$

A unit change in consumer cosmopolitanism leads to an increase of 44 percent in the foreign travelling. Also a unit change in gender leads to an increase of 23 percent in the foreign travelling. These two variables, respectively, are followed by education $(19 \%)$.

In the second regression model, our dependent variable is consumer cosmopolitanism.

Model 2. $\quad \mathrm{y}=2,694+0,372 \mathrm{x}_{1}-0,151 \mathrm{x}_{2}+0,247 \mathrm{x}_{3}+\mathrm{e}$

The most influential independent variable is foreign travelling. A unit change in foreign travelling leads to an increase of 37 percent in consumer cosmopolitanism. There is a significant and negative relationship between consumer cosmopolitanism and age. A unit change in age leads to a decrease of 15 percent in the consumer cosmopolitanism. Furthermore, a unit change in education leads to an increase of 24 percent in consumer cosmopolitanism.

\section{Summary and Conclusions}

A cosmopolitan consumer can be shortly described as: an open-minded individual whose consumption orientation transcends any particular culture, locality or community and who appreciates diversity including trying products and services from a variety of countries (Riefler and Diamantopoulos, 2009). The present study aims to examine consumer cosmopolitanism as an important predictor of consumer behaviour such as foreign travelling in Turkey as well as with demographic variables. Our second purpose is to examine foreign travelling as an antecedent of consumer cosmopolitanism as well 
as with demographic variables. We carried out surveys on 390 consumers in Turkey. We performed exploratory and confirmatory factor analyses, Pearson correlation analysis, reliability and validity analyses and multiple regression analyses. As a result of our research, foreign travelling is the most effective variable which increases consumer cosmopolitanism. The second most effective varible is education. Consumers who increase their knowledge with education, orient themselves easily with different cultures. At the same time, they also assimilate innovations which are the result of globalization and advanced technology, faster. In today's environment, consumer cosmopolitanism is a significant predictor for the purchase decisions of consumers who improve themselves culturally, follow innovations faster and wants to cross borders. Consequently, consumer cosmopolitanism is the main factor of foreign travelling.

\section{References}

Abraha, D., Radon, A., Sundström, M., and Reardon, J. (2015). The effect of cosmopolitanism, national identity and ethnocentrism on Swedish purchase behavior, Academic and Business Research Institute.

Altintas, M. H., Kurtulmusoglu, F.B., Kaufmann, H.R., Harcar, T., and Gundogan, N. (2013). The Development and Validation of a Consumer Cosmopolitanism Scale: The Polar Opposite of Xenophobic Attitudes, Ekonomska istrazivanja-Economic Research, 26(1), 137:154.

Bagozzi, R. P. and Yi, Y., (1988). On the evaluation of structural equation models, Journal of the Academy of Marketing Science, 16(1), 74-94.

Beck, U. (2002). The cosmopolitan society and its enemies. Theory, Culture \& Society, $7(2-3), 295-310$.

Bentler, P. M. (1992). On the fit of models to covariances and methodology to the Bulletin, Psychological Bulletin, 112, 400-404.

Bollen, K. A. (1989). A new incremental fit index for general structural equation models, Sociological Methods and Research, 17, 303-316.

Byrne, B. M. (2010). Structural Equation Modeling with AMOS Basic Concepts Application and Programming (Second Edition), Routledge Taylor and Francis Group.

Cannon HM, Yoon SJ, McGowan L, and Yaprak A. (1994). In search of the global consumer. Annual meeting of the Academy of International Business, March.

Cannon, Hugh M. and Yaprak, A. (1993). Toward a Theory of Cross-National Segmentation, Annual Conference of the Academy of International Business.

Cannon, H. M., and Yaprak, A. (2002). Will the real-world citizen please stand up! The many faces of cosmopolitan consumer behavior. Journal of International Marketing, 10(4), 30-52.

Carpenter, J. M., Moore, M., Alexander, N., and Doherty, A. M. (2013). Consumer demographics, ethnocentrism, cultural values, and acculturation to the global consumer culture: A retail perspective. Journal of Marketing Management, 29 (34), 271-291. 
Cleveland, M., Laroche, M., and Papadopoulos, N. (2009). Cosmopolitanism, consumer etnocentrism and materialism: An eigh country study of antecedents and outcomes. Journal of International Marketing, 116-146.

Cleveland, M., Papadopoulos, N., and Laroche, M. (2011). Identity, demographics, and consumer behaviors: international market segmentation across product categories. International Marketing Review, 28(3), 244-266

Cleveland, M., Laroche, M., Takahashi, I., and Erdogan, Secil (2014). Cross-linguistic validation of a unidimensional scale for cosmopolitanism, Journal of Business Research, 67, 268-277.

Dye T.R. (1963). The local-cosmopolitan dimension and the study of urban politics. Soc Forces, 41:239-46.

Earle TC, and Cvetchkovich G. (1997). Culture, cosmopolitanism, and risk management. Risk Anal, 17(1):55-65.

Engel, K. S., Moosbrugger, H., and Müller, H. (2003). Evaluating the Fit of Structural Equation Models: Tests of Significance and Descriptive Goodness-of-Fit Measures, Methods of Psychological Research, 8(2), 23-74.

Fornel, C., and Larcker D. F. (1981). Evaluating structural equation models with unobservable variables and measurement error, Journal of Marketing Research, 18(1), 39-50.

Hair, JF., Anderson, Re., Tatham, Rl., and Black, Wc. (1998). Multivariate data analysis. 5th ed. Upper Saddle River, NJ. Prentice-Hall.

Jain AK and Etgar M. (1977). Overlap in retail outlet and product innovator characteristics. J Retail; 53(2):63-75.

Jennings, M.K. (1966). Pre-adult orientations to multiple systems of government. Working paper. Ann Arbor: Survey Research Center, University of Michigan.

Marsh, H. W. and Hocevar, D. (1985). An application of confirmatory factor analyses to the study of self-concept: First and higher order factor models and their invariance across groups, Psychological Bulletin, 97, 562-582.

Merton, R.K. (1957). Patterns of influence: Local and cosmopolitan influential. Social Theory and Social Structure. New York: The Free Press, 387-420.

Nunnally, J. C. and Bernstein, I. H. (1994). Psychometric Theory, 3rd ed., New York, McGraw-Hill.

Parts, O. and Vida, I. (2011). The Effects of Consumer Cosmopolitanism on Purchase Behavior of Foreign vs. Domestic Products, Managing Global Transitions, 9 (4): 355-370

Riefler, P. and Diamantopoulos, A. (2009). Consumer cosmopolitanism: Review and replication of the CYMYC scale, Journal of Business Research, 62, 407-419.

Riefler, P., Diamantopoulos, A., and Siguaw, J. A. (2012). Cosmopolitan consumers as a target group for segmentation. Journal of International Business Studies, 43, 285-305.

Robinson JP and Zill N. (1997). Matters of culture. Am Demogr, 19:48-52. 
Saran, A. and Kalliny, M. (2012). Cosmopolitanism: Concept and Measurement, Journal of Global Marketing, 25:5, 282-291.

Skrbis, Z., Kendall, G. and Woodward, I. (2004). Locating cosmopolitanism between humanist ideal and grounded social category. Theory, Culture \& Society, 21(6), 115-136.

Skrbis, Z., and Woodward, I. (2007). The ambivalence of ordinary cosmopolitanism: Investigating the limits of cosmopolitan openness. The sociological review, 55(4), 730-747.

Vida, I., Dmitrovic, T., and Obadia, C. (2008). The role of ethnic affiliation in consumer ethnocentrism. European journal of marketing, 42(3/4), 327-343.

Yoon, S-J., Cannon, H.M. and Yaprak, A. (1996). Evaluating the CYMYC Cosmopolitanism Scale on Korean Consumers, Advances in International Marketing, 7:211-232.

Yoon, S.J. (1998). Dimensionality of the Cosmopolitanism Construct: Cross-Method Validation of the Emic and Etic Interpretations, in AP - Asia Pacific Advances in Consumer Research Volume 3, eds. Kineta Hung and Kent B. Monroe, Provo, UT : Association for Consumer Research, Pages: 81-88. 